\title{
Scientific and Methodological Bases of Creating Electronic Textbooks on Biology in the English language
}

\author{
Temirgazina Zifa Kakbaevna ${ }^{1}$, Kaparov Cerjan Eglambekovych ${ }^{1}$, \\ Abramova Anna ${ }^{1}$ and Khamitova Gulmira Abuovna ${ }^{2}$ \\ ${ }^{1}$ Pavlodar State Pedagogical Institute 60 Mira St., Pavlodar, 140003, Kazakhstan. \\ ${ }^{2}$ Innovative University of Eurasia 45 Lomov St., Pavlodar, 140000 Kazakhstan.
}

DOI: http://dx.doi.org/10.13005/bbra/1957

(Received: 05 July 2015; accepted: 20 September 2015)

\begin{abstract}
The article describes the concept of an electronic textbook on Biology in English, developed for the purpose of implementing multilingual education in the secondary schools of the Republic of Kazakhstan with Russian as a language of instruction. The described type of the electronic textbook is a closed one; its advantages over the open type are revealed. The advantages of the electronic textbook compared with a conventional one (paper) are explained, in particular, its didactic possibilities concerning polyperceptual impact on a student's perception, control over the assimilation of knowledge and skills, interactive process of assimilation and control. Basic methodological principles of the electronic textbook are determined: teaching a subject through the English language; modular and thematic principle of the textbook content; minimizing the theoretical text material, the emphasis on voicing and visualization of the content; technical accessibility for main users - subject teachers and students. The structure of the textbook, which consists of three main components, is presented in detail: presentation, training and supervision. Adobe Flash CS4 is chosen as a lookup programme for the textbook. The programme has wide interactive and animation capabilities that are sufficiently technically available for the main users - subject teachers and students. The article also deals with the problems of translation of biological terminology into English.
\end{abstract}

Key words: electronic textbook, multilingual education, biology, closed electronic textbook, modular and thematic concept, module, tests, animation, terminological vocabulary, methods of translation.

Today creation of electronic textbooks (hereinafter - ET) on biology in the English language for secondary general education schools is one of the most pressing problems of the Kazakh education and the higher pedagogical school of Kazakhstan and teachers should take an active part in order to solve it. The relevance of this research is provided by a number of socially important factors:

\footnotetext{
* To whom all correspondence should be addressed.
}

a) firstly, the need to implement the cultural project "Trinity of languages" outlined in the message of N.A. Nazarbayev, President of the Republic of Kazakhstan "New Kazakhstan in the new world” (President's message, 2007) and the Concept of multilingual education, adopted in the Republic of Kazakhstan, in the learning process (Zhetpisbayeva, 2009);

b) secondly, special attention to the teaching of science and math in secondary schools of Kazakhstan;

c) thirdly, the requirement for educational 
process to be computerized in secondary schools, which was stated in the Kazakh educational project "e-learning".

From the school years of 2007-2008, the Ministry of Education and Science of Kazakhstan launched the new educational project aimed at introducing education in three languages in 31 special schools for gifted children. This became one of the main directions to improve the quality of education to international standards.

Implementation of this project envisages annual increase in the number of classes and the gradual transition of the whole school system to the education in three languages. According to the order of the MES, the Education departments were instructed to organize activities of specialized schools for the implementation of trilingual teaching of general subjects from the 7th form, as well as envisage the teaching of one or more subjects of the natural-mathematical cycle in English, Kazakh language, and literature, history of Kazakhstan in schools with the Russian language of instruction - in the Kazakh language by the programmes of schools with the Kazakh language of instruction; Russian language and literature in schools with the Kazakh language of instruction - in the Russian language, by the programme of schools with the Russian language of instruction.

However, despite positive changes and some achievements of Kazakhstan's secondary schools, a number of difficulties appeared in the introduction of multilingual education. They primarily refer to the lack of pedagogical staff capable of teaching the subjects of the naturalmathematical cycle in the English language and lack of teaching aids for these subjects in English. For example, there are no teaching materials for teaching biology in the English language in secondary schools that are created in compliance with the Kazakh State education standards, model programs, and, more importantly, in view of the Kazakh teaching traditions of the subject in secondary schools. Existing biology textbooks in English that are used, for example, in KazakhTurkish Lyceums, do not fully meet the requirements listed above.

Due to the urgent need in textbooks on the subjects of the natural-mathematical cycle (including biology) in the English language, which comply with the state educational standards of the Republic of Kazakhstan, as well as the need in e-textbooks, the development of electronic textbooks provides opportunities for breakthrough results in secondary education in the field of multilingual education and for going to a new level - the level of e-learning.

Developed ET are designed to provide scientific and methodological support of teaching such an important subject of the science and math cycle as biology in the English language for pupils of the 7-8th forms of secondary schools with the Russian language of instruction. Proposed textbooks are compiled on the basis of the current curriculum of the "Biology" subject, approved by the Ministry of Education and Science of Kazakhstan, according to the age characteristics of students.

The group of authors that works on the creation of textbooks includes experienced teachers-biologists, experts in IT-technologies with extensive experience in the creation of lookup programmes for various teaching aids, English language specialists, engaged in translation and content adaptation. The proposed project has large groundwork and preliminary results, obtained in the course of the experiment on the introduction of multilingual education within the framework of the experimental area, created by PSPI (Pavlodar State Pedagogical Institute) based on the gymnasium No.3 (a type of school with a strong emphasis on academic learning) of Pavlodar in 2012. So, the teachers of biology of the 7-8th forms tested the informative modular and thematic principle for the selection of theoretical material in Russian and its translation into English, the system of assignments and exercises on biology is created in view of the multilingual approach.

\section{Methodology and methods.}

We selected the following research methods: methodical experiment, content analysis of didactic concepts and school textbooks, computer programming, a set of translation methods.

During the project implementation, we developed methodological principles of creating school electronic textbooks for multilingual education:

1) Teaching the subject via the English language;

2) Modular and thematic principle of the 
content structure;

3) Technical availability for users;

4) Minimization of the amount of theoretical material;

5) Focus on visualization and interaction.

The above mentioned methodological principles of ET development are described in more detail below. Electronic biology textbooks in English for students of the 7-8th forms are based on a fundamentally important original methodological position - teaching biology in English, rather than teaching English through the subject of "Biology”, as it is often seen in today's practice of multilingual education in secondary schools of Kazakhstan with a particular language of instruction. This practice leads to the fact that the knowledge of English becomes a priority for the teacher at the expense of their subject competencies in biology.

In other words, students must fully assimilate the knowledge and skills on biology, master the biological terminology and the academic style in the English language. This principle allows students to acquire solid knowledge and the necessary competence on the subject of "Biology". Deep understanding of this principle should underpin the concept of the textbook - the English language is a means of mastering "Biology" by students, for whom the main language of instruction is Russian, i.e. the textbook should be built in view of two languages: English, in which an individual subjects is taught, and Russian main language of instruction (Temirgazina et al., 2015). Inclusion of this principle is shown in the selection and formulation of assignments and exercises, many of which are based on matching English and Russian terms and vice versa, matching definitions in one language and the terms in another language, and the fact that the theoretical text material in English is accompanied by its translation into Russian, etc.

Another fundamental approach to the biology ET development in the English language is a modular and themed content structuring principle - theoretical knowledge and a set of exercises, tests and assignments. The third principle, which underpins the development of ET, is a principle of minimizing theoretical texts in English to a necessary extent. In accordance with this principle, a significant load of the knowledge assimilation and skills formation accounts for various multimedia tools of listening comprehension, visualization and animation. And the fourth principle is technical availability for the main users - subject teachers and students.

The development of ET itself included four main phases, during which the following tasks were carried out:

a) Specification of the sources and content, i.e. informative thematic material that will be included into biology textbooks for the 78th forms;

b) Final specification and adjustment of a set of assignments and exercises that accompany each module and theme so that students acquire knowledge and form skills from the point of view of multilingual learning and a competence-based approach;

c) Translation of content into English;

d) Creation of an electronic lookup programme on the Adobe Flash CS4, software and hardware platform.

The writing group relied on fundamental Kazakh state standards (SES RK, 2005), and standard programmes (Standard programmes..., 2010) in the education sphere, which relate to the textbook content and the requirements for ET, as well as the achievements of foreign researchers in the creation of electronic educational resources (Belyaev et al., 2002; Demkin et al., 2002).

\section{RESULTS}

\section{Characteristics of the textbook electronic form.}

The ubiquitous dissemination of information and multimedia technologies create new directions in the informatization of school education. Means of informatization are used both in the actual training of students and when dealing with the various issues related to the organization of education. E-learning tools play the main role in the process of education informatization. These primarily refer to electronic textbooks. A modern electronic textbook is an educational and methodological complex that allows students to master a training course or its section at the level of knowledge and skills independently or with the help of a teacher. Like traditional textbooks, etextbooks must be of high scientific and methodological level, fully comply with the state 
educational standard, its didactic units and a standard program of the subject. There is also a requirement to ET to ensure continuity and completeness of the didactic cycle of the learning process, subject to interactive feedback. An electronic edition can partially or completely replace the traditional textbook or complement it. Like all e-learning tools used in the educational process, electronic textbooks must meet the general-didactic requirements: academic nature, availability, problematicity, clarity, systematic nature and consistent presentation of material, awareness of training, independence and active work, assimilation of knowledge, unity of educational, developmental and upbringing functions.

Practice shows that the creation of an electronic textbook does not mean the translation of a traditional (even it is very good) textbook in the electronic format, accompanied by navigation, i.e. creation of hypertexts and illustrating material with the help of multimedia and the embodiment of the texbook on a computer screen. An electronic textbook fulfils a fundamentally different function compared to the usual textbook that is why printing the content of ET always leads to the loss of its specific didactic properties and primarily, its interactivity, dynamism (Ageev, 1997; Polat 2005).

The use of ET in the educational process gives pedagogues ample additional teaching opportunities, which primarily include the following opportunities:

a) Feedback between users (teacher, pupil) and the ET, i.e. an interactive dialogue between them;

b) Computer visualization of information: objects, processes and phenomena (real and virtual), as well as their patterns, their representation in the dynamics;

c) Computer simulations of the studied objects, phenomena and processes;

d) Automated control over the results of assimilating the material and management processes of students' educational activity (Abramov, 2011).

The electronic textbook, developed by the writing group, consists of three main components: 1 - is a presentation part, which outlines the basic theoretical information on the subject; 2 - is a training part in the form of exercises, assignments and other forms of training, through which information passes to the category of knowledge; 3 - is a control part (tests, video tasks, software polls, etc.). The control part allows objectively assessing the students' knowledge of the biology course.

Currently, two kinds of ET are used in the teaching practice: a closed electronic textbook and an open electronic book, the so-called online textbook. The first one is a textbook on the subject area in one or another electronic format, which is immutable and independent of Internet resources. It is used on individual computers or in local networks, created by an author or a group of authors; it may have different versions and is usually distributed on CDs. An online textbook means an open textbook with the links to external sources of information and knowledge, this electronic textbook is hosted on one of the servers of a global information network. It depends on the network and can be modified (the content can be included or excluded, some elements can be replaced) depending on the changes therein. The principle of creating an open textbook is different from the closed ET. First, a structural scheme of the textbook is developed. It consists of the models of knowledge representation, which is called a semantic graph concept, hierarchical multi-level catalogue of modules and concepts, hyperlink navigation and links with applications. Then, the content of the created textbook structure is formed by experts and developers-programmers either independently or in some way of collective expertise. The structure itself (the graph of concepts) can be extended, as mentioned above, by adding new modules, concepts or giving more detail to the model of knowledge, and it can also be altered by removing, adjusting individual elements. In other words, a mobile self-developing, self-organizing learning environment is created which is constantly supported by a team of experts and is designed for Internet users (Grigoriev et al., 2002). Further development of the open ET in terms of the technical sphere and content depends on the assessment results of quality and effectiveness of training with its use. However, we should mention a flaw of an online textbook, as currently it is impossible to automate the process of its quality and efficiency assessment. This problem can be partially solved by analysing the test results of the knowledge of a student, who used 
an open textbook in the learning process. Regular analysis and ongoing diagnostics of students' knowledge may help the writing group to improve the textbook to a certain extent.

The electronic textbook on Biology, referred to in our work, is of closed nature, does not depend on the Internet environment, and allows fully carrying out the control over knowledge assimilation and skills formation of students in the educational process, as opposed to an open ET. Next consider the following important advantage of an electronic textbook, compared to a conventional textbook.

For the effective learning, the use of several kinds of perception, used in combination (i.e. simultaneously) or alternatively in a certain sequence, in the learning process is essential. As practice shows, according to the efficiency level, the most important and effective perception types are the combined ones, such as visual-acoustic, or tactile-visual or olfactory-visual-acoustic, etc. Followed by visual perception and auditory perception. Thus, the simultaneous influence of a set of stimuli on various perceptual analysers has a special power of emotional and psychological impact on the mind, memory and mental activity of students. Students that receive information through the electronic means of learning, which actively influence their sensory perception in different combinations, are affected by a powerful flow of qualitatively unusual information that creates the necessary emotional basis, on which it is much easier to move from sensory images to rational logical thinking.

An electronic textbook facilitates understanding and remembering (active and not passive) of the most significant concepts, theoretical provisions and examples to the maximum, as it involves such capabilities of a human brain into the learning process that are different than the ones involved by a conventional textbook, in particular, auditory, visual (especially related to the movement of objects) and emotional memory. Due to its specificity, electronic textbooks significantly improve the quality of visual and acoustic information; it becomes brighter, more colourful, and more dynamic. In addition, with the use of electronic textbooks in the teaching process, formation methods of visual and auditory information change drastically. So, if the traditional visual learning necessarily presupposed a particular object under study, the use of computer technology allows you to dynamically interpret not only the essential properties of real objects, but also abstract phenomena: scientific laws, theories, and concepts. Accordingly, the advantage of using electronic textbooks in the educational process is also substantiated by their enormous potential in terms of more effective influence on the sphere of students' perception in comparison with traditional ("paper") textbooks.

Given the above, as a lookup programme the writing group selected software for the textbook that implements the multimedia advantages in the teaching process to the fullest. The referred software is Adobe Flash CS4. Currently, website developers resort to the means of Flashtechnologies more and more often. This technology allows creating navigation elements, animated logos, large-scale voiced animations and websites with a variety of interactive elements (Franklin, Patton 2005; Franklin, Patton 2001). Thanks to the vector graphics, which is used in Flash, animations are small in size and therefore load quickly and adapt to the size of a browser window. But the main advantage of Adobe Flash CS4 is the Action Script language, thanks to which all interactive frame elements work (Mainger, 1997). The Action Script (scripting language) allows developers to fully control Flash-frames, causing button, videos, menus, links, scrollbars to "work", perform calculations and display any conceivable information. Possibilities of a developer, who works with Adobe Flash CS4, are limited only by their imagination and the power of a computer in use. All of the capabilities and advantages of the Adobe Flash CS4 software listed above are a perfect fit for the development of electronic textbooks, in particular, textbooks designed for schoolchildren.

It should be noted that the use of electronic textbooks in the educational process drastically changes the teaching methods in general. So, for example, forms and methods of educational material delivery, methods of its assimilation, control forms, as well as, of course, the nature of interaction between a student and a pedagogue change significantly. At the same time, we understand that the proposed electronic textbook cannot fully replace traditional approaches to learning; it only increases their 
efficiency to a great extent. The most important thing for the teacher of Biology is to find an optimal variant of using an e-learning resource in the educational process. Every type of lesson can be conducted with full or partial use of ET didactic possibilities.

The electronic textbook offered to teachers-biologists, is especially convenient as it has a large number of illustrations, colour schemes, flash animations, videos, clarifying the meaning of theoretical material. They contribute to the integral perception of information; students acquire deeper knowledge of a certain topic. To solve this problem, the headings "That's interesting", "Glossary" contain additional material, which is designed for the most inquisitive students. The textbook is also valuable due to the fact that after each lesson topic it offers sets of multi-level tasks, aimed at development of intellectual skills, in accordance with the Bloom's Taxonomy.

Printed and electronic publications that meet the following criteria are selected as sources of information:

a) Most fully correspond to the standard programme,

b) Concise and easy for creating hypertexts,

c) Contain a large number of drawings, photographs, examples and problems,

d) Are available in convenient formats, i.e. correspond to the principle of collection.

The writing group structured the selected content into sections, consisting of modules that are of minimum volume, but with the closed content, and compiled a list of concepts that are necessary and sufficient to master the subject. Texts of the sources were processed in accordance with the table of contents and structure of the modules; texts, which were not included in the lists, were excluded, and the texts that are missing from them were added; the relationships between modules were determined, as well as other hypertext links. Thus, a draft of hypertext in Russian was prepared for translation and subsequent computer implementation. As a result, a working draft of the electronic publication in Russian was created and adapted for educational purposes; it became the basis for the translation into English.

During further computer support, the electronic textbook improved, different multimedia tools were used for the purposes of voicing and visualization. So, to get the best visual aspects, we developed the scenario of modular visualization using pictures, graphics and animations that helped reducing text information on the screen to the greatest extent and using emotional memory of students effectively in order to facilitate understanding and memorizing of the material under study.

The electronic textbook is accompanied by the user's manual for its intellectual core, which should facilitate its intensive interactive use for teachers and students.

\section{The content of the textbook}

In the opinion of well-known teachers and methodologists, the biology course refers to one of the most conservative subjects of middle school, and it applies both to the educational content and methods of teaching. Over the last two decades in Kazakhstan, on the basis of the half a century of experience in the systematic teaching of biology in the Soviet school, a highly methodical system of education is established. This system also includes an effective system of training teachers of biology. Every innovation in the sphere of biology teaching methods, which seeks to be widespread in schools, must be certainly built on this experience and develop it. This makes the task of adjusting the course, in accordance with the requirements of computerization and multilingual education, a quite difficult methodological problem that can be solved only through a serious experimental studies using drastic pedagogical innovations, and taking into account the historically formed features of the training of biology teachers.

In the domestic pedagogical science the leading formation principles of general education content, including biological one, have long been defined (Lerner, 1978; Lednev, 1991). With regard to our problem, the most important of these is the principle of taking into account the unity of content and process in learning, which is expressed in the following postulate: "Content does not exist outside of the learning process and available techniques, patterns, principles, and educational opportunities are taken into account in the design of the educational content". According to it, the basis for determining and compiling the content of the subject is practice. Thus, in the created electronic textbooks "Biology" for the 7th form, 
"Biology" for the 8th form, we disclosed not only the subject content (conceptual and terminological apparatus, laws, facts, types of activities), but also ways of transferring it to students and ways for the content assimilation, as well as related activities.

At the level of an academic subject, an idea of the content parts that perform specific functions in the general education is expressed. The specifics of these functions define composition and structure of the content for each school subject, including biology, which are individual but correlated with the general theoretical concept (Trifanova, 2001). The content of biological education at the level of an academic subject is implemented in the curriculum. They are the basis for the selection of appropriate didactic teaching material for textbooks on Biology. The fundamental basis and the most important formation source of the biological education content at the level of an academic subject is the biological science. Therefore biology as a subject includes the content of the biological science in pedagogical interpretation.

Specific content elements, subject to the assimilation by students, disclose at the level of teaching material. It includes all the elements of the biological education content. At the level of pedagogical reality, the education content is implemented in various educational institutions: general education schools, magnet schools, gymnasiums, lyceums.

In the textbook for the 7 th form all the informative material is distributed over 15 modules which include 68 lessons, according to the number of hours in the curriculum of biology. Modules can include different number of lessons. For example, the 1st module contains 7 lessons, 2nd module -4 lessons, 3rd Module -3 lessons, etc. If we talk about the content of each module in more detail, we should note that the first part of each topic contains general characteristics of this taxonomic group under consideration, the second part describes the variety of living organisms of the represented taxon and peculiarities of their life, prevalence and ecology. Each lesson is accompanied by a set of exercises and tasks of different difficulty levels and a glossary - a list of new terms in English learned during the lesson. Assignments are interactive, students can check if they performed them correctly themselves. There is a heading called “That's interesting” for certain topics that “deepen” students' knowledge. The textbook includes laboratory works, envisaged by the standard programme. Each module ends with the final control - tests and assignments. Also, in the end there is a glossary containing all the new terms in the module. The teacher has the ability to check and assess the knowledge after each topic and after each module. The textbook can be used both in the classroom and for individual work of students, as the textbook provides tests with answers.

The proposed textbook is designed for students with different levels of English, so in addition to the simplicity of lexical and syntactic structures of the English language, each topic is accompanied by a Russian translation, which can be used by teachers in the classrooms with the low level of language proficiency (Littlejohn et al., 2002). The content in Russian may be used in the process of explaining new material, in the process of solidifying new knowledge and to control various abilities and skills acquired by students.

\section{DISCUSSION}

Due to its specificity, the translation of electronic textbooks on Biology for the 7th and 8th forms into English is determined by two factors: firstly, the scientific and technical nature of the text and, secondly, the need to consider the age and didactic requirements for school textbooks, which makes it quite complex. Norms of the English written language with specific characteristics underpin the academic style of the modern English language. These norms refer to the following ones:

\section{Vocabulary. Like other sciences, biology has a vast terminology.}

The language of the textbook contains a large number of special terms and words of the non-Anglo-Saxon origin. Latin and Greek are known to have had a huge influence on the development of biology as a science. No wonder that in the texts of the electronic textbook one can encounter Latin terminology in the description of species in botany and zoology, for example, Phylum Cnidaria, Annelida, Echinococcus, and as well as the words with Latin prefixes: multicellular 
animals, hermaphrodites, homogeneous, hypodermic and others.

This part of vocabulary sometimes causes difficulties for translators. But there are traditional translation methods for such terms, these methods have been used in the English text of the ET. Transliteration is among them, for example, inhibitor - , hydra , pharynx , as well as long-held translation equivalents: coelenterates , intestine, tapeworm humus and others. The source of the traditional translation methods is specialized lexicographical sources (The Environment Encyclopedia and Directory, 2005, The New English-Russian Dictionary of Biology, 2009; Glossary of Biodiversity Terms). One more group of terms is used as conventional scientific terminology (internationalisms). This vocabulary can be used both in non-terminological and terminological sense. The task of the translator is to correctly interpret the meaning of terms and internationalisms in the context and provide the most accurate information transfer. We refer to such lexemes as: parasite, capsules, cuticle and others.

Various lexical and grammatical classes of words, used to describe the basic concepts of biology, participate in the creation of biological terms: nouns (nutrition, respiration, excretion), adjectives (intracellular, extracellular, digestive), verbs (capture, breathe, absorb), adverbs (throughout, sexually) and others. Function words (prepositions and conjunctions) and words that provide connections between the individual elements of statements (mainly adverbs) play a big role, for example: - Firstly liver fluke produces a lot of eggs, and secondly its larvae are reproduced asexually: embryos are divided many times. Many cnidarians have both life forms (both generations) which follow each other (alternate) throughout the life cycle, from birth to death of the organism. Some (hydra, coral polyps) are not free-floating forms (jellyfish). Others (some scyphomedusae) lost form of polips.

As we can see, the English language makes a certain contribution to the formation and development of the terminological base of modern biology.

\section{Grammar}

Passive, impersonal and indefinitepersonal structures are widely used in the translation of biological texts from Russian into English These annular segments are located not only on the surface but also inside the body; - There are some of them which do harm to the human health and different livestock. It seems that the long hair became alive. The combination of the Russian verb áûoü (byt') and a short form of the passive participle is one of the most common variants of translating English passive constructions, along with the use of the passive verb ending with -ñy (sya), in the proposed textbook.

Compound and complex sentences, in which nouns, adjectives and impersonal forms of the verb prevail, are often used in the textbook. Livestock are infected by liver fluke during drinking water or eating grass with the cysts;

Therefore, the bodies of these organisms are arranged in such a way that the protection means or grabbing prey tentacles are pointing in different directions like rays (or radius) from a single center. In order to translate this kind of structures, a translator needs to possess knowledge about the differences in sentence structures, word order in a sentence.

The method of information delivery. The main objective of academic literature is to deliver certain information to students clearly and accurately. This is achieved by delivering information in a logically substantiated manner without the use of emotionally coloured vocabulary, expressions and grammatical structures, for example:Digestive system includes a straight pipe, begun with mouth, surrounded by three cuticular lips and finished by rectal . - All coelenterates are aquatic animals, most of which inhabit the seas and oceans. They inhabit sea from the surface to extreme depths, from tropical waters to Polar Regions. As a rule, such simple short sentences, even though they are saturated with terms, do not cause particular difficulties for the perception of pupils of the 7-8th forms.

\section{CONCLUSION}

Thus, in the course of this project, electronic textbooks on biology in English have been developed for pupils of the 7-8th forms with Russian as a language of instruction. These textbooks will be in demand in general and specialized schools of Kazakhstan, which implement multilingual education in the educational 
process. In the future, we consider it expedient to create an academic bilingual mini-dictionary with a special (biological) vocabulary. Knowledge of the terminology system of the English language in the sphere of Biology broadly promotes the formation of the biological foundation of international education.

Electronic textbooks on Biology for the 7-8th forms in the English language, created in view of the SES of Kazakhstan, are primarily intended for the target audience - teachers-biologists of Russian speaking secondary general education schools of Kazakhstan, where multilingual education is being introduced. Principles of creating electronic textbooks on natural and humanitarian subjects in the English language, adapted for Kazakh schools, can be used to generate create ET on physics, chemistry, mathematics, etc. in the English language for schools with the Kazakh language of instruction. Accordingly, these principles can be extended and popularized in the scientific and methodical community of Kazakhstan, the CIS countries and the world scientific community.

\section{ACKNOWLEDGEMENTS}

The work was funded with the intramural research grant. We express our deep gratitude to the staff of the Pavlodar State Pedagogical Institute and directly to its head, Doctor of Philosophy, Arshabekov Nurgali Rahimgalievich for the opportunity to realize our ideas.

\section{REFERENCES}

1. Abramova, Yu.N., Basic Principles of Creating an Electronic Textbook on Higher Mathematics. Bulletin of the Tambov University, 2011; 4(16): 1022-1023.

2. Ageev, V.N, Electronic Book: New Means of Social Communication. Moscow: Mir Knigi, 1997.

3. Belyaev, M.I., V.M. Vymyatin, S.G. Grigoriev et al., The Theoretical Basis for the Creation of Educational Electronic Editions. Tomsk: Publishing house of Tomsk University, 2002.

4. GOST RK 34.017-2205, Electronic Textbook. Requirements for the Composition, Functions, Content, Design and Documentation. Astana, 2005.

5. Grigoriev, S.G., G.A. Krasnova, I.V. Robert et al., Development of the Concept of Educational Electronic Editions and Resources. Open and Distance Education, 2002; 3(7).

6. Demkin, V.P. and V.M. Vymyatin, Principles and Technology for Creating Electronic Textbooks. Tomsk: Publishing house of Tomsk University, 2002.

7. Zhetpisbayeva, B.A., Theoretical and Methodological Foundations of Multilingual Education, Thesis for the degree of Doctor of Pedagogical Sciences, Karaganda, 2009.

8. Lednev, V.S., Content of Education: Nature, Structure and Prospects (2nd ed., revised). Moscow: Vysshaya shkola, 1991.

9. Lerner, I.Y., The Composition of the Education Content and the Ways of its Implementation in the Textbook. In Problems of a School Textbook: Collection of Articles (Vol. 6). Moscow: Prosvescheniye, 1978; 46-64.

10. Mainger, D., Java Script: Fundamentals of Programming. Kiev: Publishing Group BHV. 1997.

11. Chibisova, O.I. (Ed.), New English-Russian Biological Dictionary. Moscow: ABBYY Press, 2009.

12. Polat, U.S., New Pedagogical and Information Technologies in the Education System. Moscow: Academia, 2005.

13. Message of the President of the Republic of Kazakhstan N.A. Nazarbayev "New Kazakhstan in the new world" of February 28, 2007. Date Views 20.09.2015 akorda.kz/ru/page/ page_poslanie-prezidenta-respublikikazakhstan-n-nazarbaeva-narodu-kazakhstana28-fevralya-2007-g_1343986887.

14. Temirgazina, Z.K. et al., Concept of an Electronic Textbook on Biology in the English Language for Schools with the Russian Language of Instruction. Pedagogical Bulletin of Kazakhstan, 2015; 2: 57-63.

15. Trifanova, V.N., The Content of Education and Its Display in Teaching Aids, Thesis of Candidate of Pedagogical Sciences, Moscow, 2001.

16. Typical Secondary School Programme of Kazakhstan. Date Views 20.09.2015 e.edu.kz/ 72/-/document_library_display/Fj6e8E7L H9PK/view/4796479.

17. Littlejohn, A., D. Hicks and O. Vinogradova, 2002. Cambridge English for Shools in Russia. Students Book Four. Cambridge University Press, Drofa Publishers.

18. Glossary of Biodiversity Terms. Date Views 20.09.2015 www.unep-wcmc.org/reception/ glossary.htm.

19. Derek, F. and P. Brooks, Flash 5! Creative Web 
Animation. Berkeley: Peachpit Press, 2005.

20. Derek, F. and P. Brooks, 2001. Expert Flash Tips and Tricks. Date Views 20.09.2015 http:/ /www.peachpit.com/articles/article.aspx? $\mathrm{p}=20711$.

21. The Environment Encyclopedia and Directory (4th ed.), London, New York: Routledge, 2005. 